\title{
Copolyimide mixed matrix membranes with oriented microporous titanosilicate JDF-L1
} sheet particles

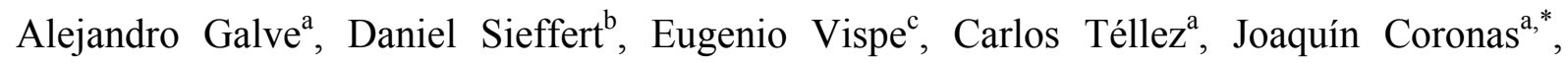
Claudia Staudt ${ }^{\text {b,* }}$

${ }^{\mathrm{a} C h e m i c a l}$ and Environmental Engineering Department and Nanoscience Institute of Aragon, Universidad de Zaragoza, 50018 Zaragoza, Spain

${ }^{\mathrm{b}}$ Institute for Organic and Macromolecular Chemistry, Heinrich-Heine-University of Düsseldorf, Universitätsstraße 1, 40225 Düsseldorf, Germany

${ }^{\mathrm{c}}$ Instituto Universitario de Catálisis Homogénea (IUCH), Universidad de Zaragoza-CSIC, 50009 Zaragoza, Spain

*Corresponding authors: coronas@unizar.es, staudt@uni-duesseldorf.de

\begin{abstract}
JDF-L1 is a microporous titanosilicate exhibiting a layer structure with pore sizes of about $3 \AA$. It is consequently an attractive material to separate $\mathrm{H}_{2}$-containing mixtures. This is the reason why JDF-L1, after disaggregation by means of hexadecyltrimethylammonium surfactant, has been combined with a carboxyl group containing copolyimide (6FDA4MPD/6FDA-DABA 4:1) to produce mixed matrix membranes, which were applied to the separation of $\mathrm{H}_{2} / \mathrm{CH}_{4}$ and $\mathrm{O}_{2} / \mathrm{N}_{2}$ mixtures. Additionally, due to the sheet growth habit of JDFL1 crystals, a preferential horizontal orientation of the JDF-L1 filler particles dispersed into the polymer was expected. This preferential orientation, which was achieved when the polymer solution concentration used during the membrane casting process was relatively low, has been studied by optical and electronic microscopy, X-ray diffraction and polarized Raman spectroscopy.
\end{abstract}


Keywords: Mixed matrix membrane; Gas permeation; Microporous titanosilicate; JDF-L1; Zeolite; Copolyimide 


\section{Introduction}

The first mixed matrix membranes (MMMs) were discovered in the 1980's and increasingly investigated in recent years[1]. They consist of an organic (polymeric) and an inorganic phase, with the latter being dispersed as a filler within the polymer matrix. Research interest has grown because MMMs are a promising approach to improve membrane separation properties above the so-called Robeson upper bound limit[2]. This is because they can combine the advantages of inorganic and polymeric membrane materials. The most prominent characteristics of inorganic membranes are their superior separation characteristics whereas polymeric membranes are easy to produce at low cost.

Filler materials can be divided into different types depending on their shape and structure. Most commonly, particulate inorganic materials are used in MMMs. In recent years however, interest has risen in sheet-shaped fillers which are called flakes or nanosheets, if one of the dimensions is in the nanometer range. Depending on the possibility of the feed components to permeate through such filler materials, they are subdivided into selective and non-selective fillers, which furthermore can be incorporated into MMMs in random or distinct parallel orientation. In this work, the inorganic filler has a high aspect ratio and it was attempted to orientate these inorganic nanosheets horizontally inside the MMMs.

In some previous works, attempts have been made to orientate non permeable inorganic sheets in different polymers and it was found that the orientation has a great influence on the permeability[3-6]. A comparable improvement of the separation characteristics can be achieved with smaller amounts of oriented fillers as with higher loads of non-oriented filler. Predictions of the permeation properties of mixed matrix membranes with sheet shaped inorganic fillers have been made. For instance, Yang et al.[3] proposed a model for oriented non-selective sheets, later modified by Sheffel and Tsapatsis[7] for selective flakes. 
Lamellar materials have been claimed to be good catalysts[8-11] and their application as inorganic fillers in mixed matrix membranes are well known[12-14]. Being lamellar, often after swelling-exfoliation processes, they usually have a high aspect ratio, which allows casting of thin mixed matrix membranes. Due to their microporous structure, the selectivity of the membrane can be improved by size exclusion.

JDF-L1 is the layered microporous titanosilicate used as the inorganic phase in the MMMs presented in the this work. The material was also reported as AM-1[15, 16] and NTS[17] titanosilicate, whose structure was discovered by Roberts et al. in 1996[18] and more recently refined by Ferdov et al.[19]. It is described by the chemical formula $\mathrm{Na}_{4} \mathrm{Ti}_{2} \mathrm{Si}_{8} \mathrm{O}_{22} \cdot 4 \mathrm{H}_{2} \mathrm{O}$ and it consists of five-coordinated $\mathrm{Ti}(\mathrm{IV})$ ions in the form of $\mathrm{TiO}_{5}$ square pyramids where each of the vertices of the base is linked to one $\mathrm{SiO}_{4}$ tetrahedron $\left[\mathrm{TiO} \cdot \mathrm{O}_{4}\left(\mathrm{SiO}_{3}\right)_{4}\right]$ to form continuous sheets with exchangeable interlamellar $\mathrm{Na}^{+}$ions. From the point of view of porosity, the layers contain six-membered rings composed of two square pyramids and two pairs of tetrahedra, running along the [001] direction. The structure is shown in Figure 1. JDF-L1 can be synthesized by hydrothermal synthesis which provides particle agglomerates with a size of about $10 \mu \mathrm{m}$ and single particles of $0.1 \mu \mathrm{m} \times 3 \mu \mathrm{m} \times 3$ $\mu \mathrm{m}$ with a sheet growth habit[20].

JDF-L1 has been chosen as the inorganic filler in this work because of the pore size across the layers, which is about $3 \AA$. This is related to the aforementioned 6-membered rings (see Figure 1) which makes this material attractive for the separation of $\mathrm{H}_{2} / \mathrm{CH}_{4}$ and even $\mathrm{CO}_{2} / \mathrm{CH}_{4}$ gas mixtures. In the latter case it is important to take the basic character of titanosilicate materials into account, as shown for ETS-10 in several chemical reactions[21, 22] and $\mathrm{CO}_{2}$ adsorption[23, 24]. It is possible to exfoliate single layers of JDF-L1 to obtain delaminated UZAR-S1, which has been applied to the preparation of mixed matrix membranes[14]. 


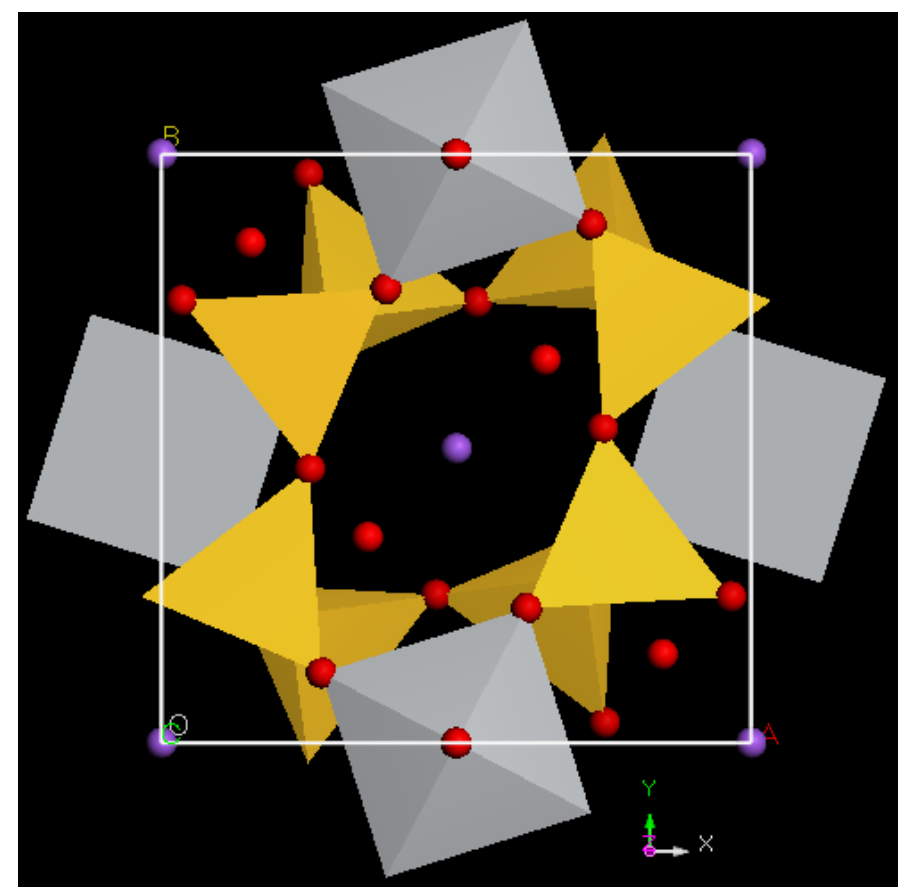

Figure 1. Structure of the titanosilicate JDF-L1 (top view onto layer, along [001] direction). Grey, $\mathrm{TiO}_{5}$ square pyramids; yellow, $\mathrm{SiO}_{4}$ tetrahedra; red, oxygen atoms (both from polyhedra corners and water molecules hydrating $\mathrm{Na}^{+}$); purple, $\mathrm{Na}^{+}$ions .

Moreover, as shown in this work, it is possible to break the agglomerates of JDF-L1 to obtain single, non-agglomerated sheet particles, about $100 \mathrm{~nm}$ in thickness, keeping all the crystalline features of the as-made material. In contrast to delamination, where single layers of the inorganic material with a thickness of few nanometers can be obtained, this process is called disaggregation. Both processes, delamination and disaggregation, are of interest when attempting to break the synthesized JDF-L1 agglomerates to obtain a material with better dispersion properties concerning the production of composite MMMs. Disaggregated JDF-L1 was chosen instead of UZAR-S1 because it was assumed that this material can be orientated easier and will still allow sufficiently high permeability with thin enough sheets. In fact, it has been reported that e.g. $0.1 \mu \mathrm{m} \times 0.1 \mu \mathrm{m}$ particles could be too small to align in PVA polymer[25]. 
Due to their excellent mechanical and thermal properties, copolyimides have been widely investigated and used as commercial membrane material in gas separation[4, 26-31]. The high rigidity of the polymer backbone leads to high free volumes and improves the gas separation properties of this class of polymers. Through the use of methyl substituted aromatic diamine monomers such as 2,3,5,6-tetramethyl-1,4-phenylenediamine (4MPD) a polymer with a highly rigid backbone can be achieved [32]. It is possible to further improve the properties of copolyimide membranes, especially in terms of plasticization, by using 3,5-diamino benzoic acid (DABA) as one of the diamine monomers. This monomer leads to a more swelling resistant material due to the formation of hydrogen bonds between the carboxylic acid groups[33]. Different dianhydrides have been investigated in previous studies and it was shown that polyimides based on 4,4'-hexafluoroisopropylidene diphtalic acid anhydride (6FDA) provide excellent properties as membranes in different separation processes. At first, such copolyimides have high solubility in different organic solvents such as tetrahydrofurane or dimethylacetamide and therefore membrane preparation is facile. Secondly, 6FDA-based polyimides show improved separation characteristics in comparison to polyimides using other dianhydrides like pyromellitic dianhydride. This is due to the fact that the bulky $-\mathrm{CF}_{3}$-side groups improve the free volume of the polymer which increases the permeability but simultaneously the $-\mathrm{CF}_{3}$-groups reduce the chain mobility which leads to an increase in selectivity[34].

For all these reasons the copolyimide 6FDA-4MPD/6FDA-DABA[35] with a diamine ratio of 4:1 (Figure 7) was combined in this work with disaggregated microporous titanosilicate JDF-L1 to produce MMMs used for the separation of $\mathrm{H}_{2} / \mathrm{CH}_{4}$ mixture. 


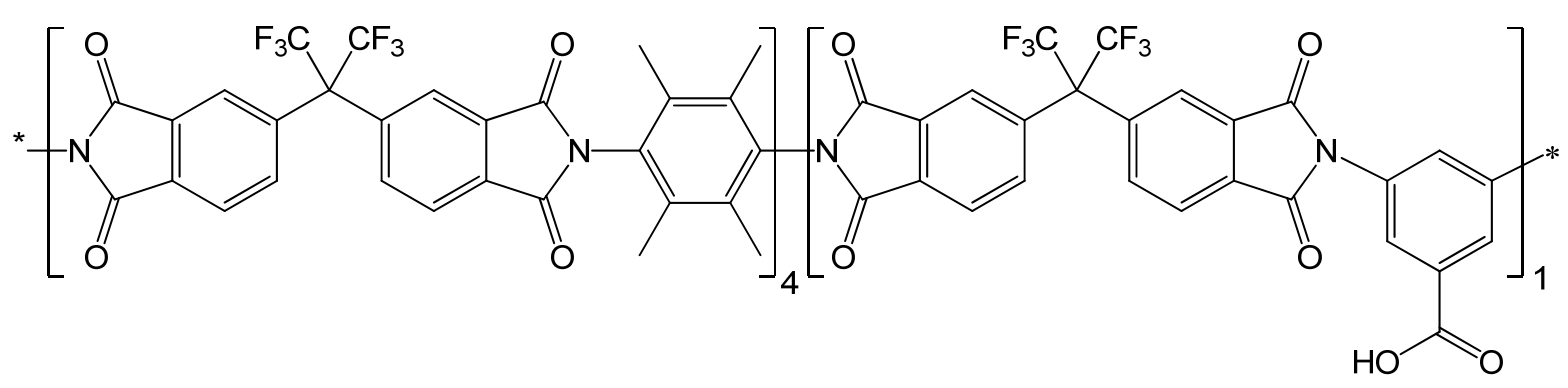

Figure 2. Structure of the copolyimide 6FDA-4MPD/6FDA-DABA 4:1.

\section{Experimental}

\subsection{Copolyimide synthesis}

The chemicals used for the copolyimide synthesis were purchased from the following suppliers: 4,4'-hexafluoroisopropylidene diphthalic anhydride (99\%) from Alfa Aesar, 2,3,5,6-tetramethyl-1,4-phenylene diamine (purum, $\geq 99 \%$ ) from Fluka and 3,5diaminobenzoic acid $(\geq 99 \%)$ as well as dimethylacetamide $(\geq 99 \%)$ from Merck. All monomers were purified by sublimation prior to their use as reactants. Dimethylacetamide was distilled before use as solvent.

The copolyimide used as polymeric material was synthesized from the dianhydride 6FDA (4,4'-hexafluoroisopropylidene diphthalic anhydride) and the diamines 4MPD $(2,3,5,6$ tetramethyl-1,4-phenylene diamine) and DABA (3,5-diaminobenzoic acid). The reaction was conducted under moisture free conditions using a $\mathrm{N}_{2}$ atmosphere. To obtain the copolyimide 6FDA-4MPD/6FDA-DABA with a diamine ratio of 4:1, four equivalents of 4MPD and one equivalent of DABA were placed in a two-neck flask and dissolved in dimethylacetamide (DMAc). After the dissolution of the diamines, five equivalents of the solid dianhydride 6FDA were added in small portions. The mixture was stirred overnight to form the polyamic acid, which was then chemically imidized. This was done using a 1:1 molar mixture of triethylamine and acetic acid anhydride, which was added in a three-fold excess referring to 
the initial amount of 6FDA. The reaction mixture was then heated up to $120^{\circ} \mathrm{C}$ for $30 \mathrm{~min}$. After cooling to room temperature, the mixture was precipitated in a 1:1 volume mixture of ethanol and distilled water. The raw polymer was subsequently milled and washed three times with ethanol before drying at room temperature overnight and afterwards under vacuum (80 mbar) at $150{ }^{\circ} \mathrm{C}$ for two days.

\subsection{JDF-L1 synthesis and disaggregation}

The chemicals used for titanosilicate JDF-L1 synthesis were purchased from the following suppliers: sodium silicate $\left(27 \% \mathrm{SiO}_{2}, 8 \% \mathrm{Na}_{2} \mathrm{O}, 65 \% \mathrm{H}_{2} \mathrm{O}\right)$ from Merck, sodium hydroxide pellets $(99 \%)$ from Scharlab, $\mathrm{TiCl}_{3}\left(20 \% \mathrm{TiCl}_{3}\right.$ solution in $\left.3 \% \mathrm{HCl}\right)$ from Alfa Aesar, hexadecyltrimethylammonium bromide (CTABr, powder, $\geq 97 \%$ ) from Sigma-Aldrich, tetrapropylammonium hydroxide (TPAOH, $40 \mathrm{wt} \%$ in water) from Merck.

JDF-L1 crystals were obtained by hydrothermal synthesis from gels of molar composition 4.2 $\mathrm{SiO}_{2}: \mathrm{TiO}_{2}: 2.9 \mathrm{Na}_{2} \mathrm{O}: 101 \mathrm{H}_{2} \mathrm{O}[20]$. To prepare $26.25 \mathrm{~g}$ of the gel, sodium silicate solution (10.05 g) was mixed with deionized water (6.54 g) and $\mathrm{NaOH}(1.42 \mathrm{~g})$; then $\mathrm{TiCl}_{3}$ solution $(8.24 \mathrm{~g})$ was added. After stirring for one hour at room temperature the resulting gel was degassed for a few minutes in an ultrasonic bath (Selecta) and transferred into a $35 \mathrm{~mL}$ teflon-lined autoclave. The crystallization was carried out at $230{ }^{\circ} \mathrm{C}$ for $96 \mathrm{~h}$. After filtering, repeatedly washing with deionized water and drying at $100{ }^{\circ} \mathrm{C}$ overnight, approximately $3.9 \mathrm{~g}$ of powder were obtained. JDF-L1 of this synthesis was added $(79 \mathrm{mg})$ as seeds to the same starting gel and submitted to a new hydrothermal synthesis at $230{ }^{\circ} \mathrm{C}$ for 24 h. The product was filtered, washed with deionized water and dried at $100{ }^{\circ} \mathrm{C}$ for $10 \mathrm{~h}$.

To obtain the disaggregated filler JDF-L1 ready for MMM preparation, dried JDF-L1 $(0.50 \mathrm{~g})$ was added to a solution of CTABr $(2.90 \mathrm{~g})$ and TPAOH $(5.90 \mathrm{~g}$ of a $40 \mathrm{wt} \%$ aqueous solution) and deionized water $(6.13 \mathrm{~g})$. The dispersion was transferred to a flask and refluxed for $16 \mathrm{~h}$ at $80{ }^{\circ} \mathrm{C}$ under stirring. Once the process was finished, the solid was cleaned 
with water and the solid was separated by centrifugation (10 min, $10000 \mathrm{rpm})$. This cleaningcentrifugation process was repeated three times. The clean solid was dried in an oven at 100 ${ }^{\circ} \mathrm{C}$ for $24 \mathrm{~h}$.

\subsection{Preparation of mixed matrix membranes}

The polymer was dissolved in tetrahydrofurane (THF) (99\%, over molecular sieve) and the solution was filtered through a syringe filter (PTFE membrane, $0.45 \mu \mathrm{m}$ pore size). 10 and 13 wt $\%$ polymer solution concentrations were used. The disaggregated inorganic filler (JDF-L1) material was added to the previously prepared polymer solution, and the obtained dispersion was stirred overnight. 5, 8, and $10 \mathrm{wt} \%$ JDF-L1 was formulated with the copolyimide. To achieve a homogeneous dispersion of the inorganic particles the casting solution was treated for 30 minutes in ultrasonic bath (ELMA Transsonic 310, $35 \mathrm{~Hz}$ ), afterwards it was stirred for 30 minutes again. This cycle was repeated three times. Before casting, the dispersion was kept under stirring for 30 more minutes. .

The dispersion was cast into metal rings, $7 \mathrm{~cm}$ in diameter, which were placed on a polyethyleneterephthalate (PET) sheet. All the casting equipment was placed on top of an adjustable table to assure horizontal alignment during the membrane formation. To prevent membrane contamination by dust particles during the evaporation of the solvent, funnels were

used to cover the metal. A paper tissue covered the funnels to avoid contamination. This system also exerts some control on the evaporation rate. As soon as all solvent was evaporated, the membrane was removed from the metal ring and the PET sheet by flushing the ring with distillated water. The membrane was finally dried in a vacuum oven at $150{ }^{\circ} \mathrm{C}$ and 80 mbar overnight.

Scanning electron microscopy (SEM) was conducted using a JEOL 6400. The samples were coated with gold and the device was operated at $20 \mathrm{kV}$. Thermogravimetric analyses (TGA) were performed in a TGA/SDTA851e system (Mettler Toledo). The membranes were 
placed in $70 \mu \mathrm{L}$ pans and heated ) up to $850{ }^{\circ} \mathrm{C}$ in an air flow $(30 \mathrm{~mL} / \mathrm{min})$ with a heating rate of $10{ }^{\circ} \mathrm{C} / \mathrm{min}$. X-ray diffraction analyses were carried out on a Rigaku/Max System diffractometer using $\mathrm{Cu} \mathrm{K \alpha}$ radiation with $\lambda=1.5418 \AA$ and a graphite monochromator. Raman spectra were collected on a Jasco NSR-3100 Raman spectrometer equipped with ZnSe wire grid polarizers and using $785 \mathrm{~nm}$ laser light. The spectra were recorded by irradiating the surface of the membrane with the laser and collecting with the polarizer in parallel and perpendicular orientation.

\subsection{Gas permeation experiments}

The membranes were tested at $35^{\circ} \mathrm{C}$ to separate $\mathrm{H}_{2} / \mathrm{CH}_{4}$, and $\mathrm{O}_{2} / \mathrm{N}_{2}$ mixtures $(50 / 50$ by volume) using the gas permeation setup presented in Figure 3. The feed mixture (global flow of $\left.50 \mathrm{~cm}^{3}(\mathrm{STP}) / \mathrm{min}\right)$ ) entered to the membrane through two Alicat Scientific mass-flow controllers at pressures above the atmospheric $(340 \mathrm{kPa})$. The membranes were held in a permeation module which consisted of two stainless steel pieces with a cavity to place an additional macroporous disk support 316LSS with $20 \mu \mathrm{m}$ nominal pore size (Mott Corporation) and gripped Viton ${ }^{\circledR}$ o-rings. The permeate side of the membrane was swept with a $1 \mathrm{~cm}^{3}(\mathrm{STP}) / \mathrm{min}$ mass-flow controlled stream of Ar at atmospheric pressure, allowing the transport of gases due to the different partial pressures created. When the $\mathrm{O}_{2} / \mathrm{N}_{2}$ mixture was tested, He was used as the sweep gas. The outgoing concentrations of $\mathrm{H}_{2} / \mathrm{CH}_{4}$, and $\mathrm{O}_{2} / \mathrm{N}_{2}$ were analyzed using an on-line gas micro-chromatograph Agilent 3000A equipped with TCD. Permeability results were obtained when steady state was reached. The separation selectivity was calculated as the ratio of mixture permeabilities. Permeabilities are presented in Barrer units $\left(1\right.$ Barrer $\left.=1 \cdot 10^{-10} \mathrm{~cm}^{3}(\mathrm{STP}) \cdot \mathrm{cm} /\left(\mathrm{cm}^{2} \cdot \mathrm{s} \cdot \mathrm{cmHg}\right)\right)$. 


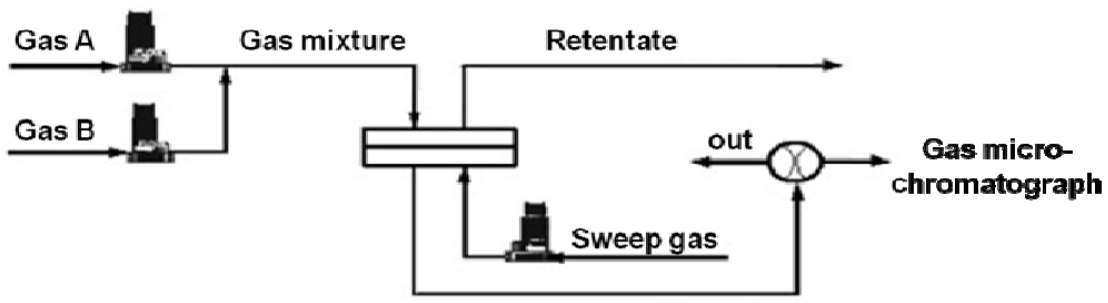

Permeate

Figure 3. Experimental setup of the gas permeation system

\section{Results}

Membranes were cast from 10 and $13 \mathrm{wt} \%$ polymer solutions with $0,5,8$, and $10 \mathrm{wt}$ \% disaggregated JDF-L1 sheet particles. As it will be shown next, due to the increase in viscosity, a more concentrated polymer solution (i.e. $13 \mathrm{wt} \%$ ) leads to a lower particle orientation. On the contrary a less viscous casting solution (i.e. $10 \mathrm{wt} \%$ ) allowed the filler particles to find a preferential horizontal orientation during the membrane preparation procedure.

\subsection{Microscopy}

Samples of JDF-L1 before and after the disaggregation process were analyzed in SEM. Figure 9 shows the as-made inorganic material after preparation by seeded synthesis (left) and disaggregated JDF-L1 treated with CTABr/TPAOH solution indicating that the aforementioned process significantly breaks up the agglomerates and produces merely sheetshaped particles. The high $\mathrm{pH}$ during the disaggregation process provided by the TPAOH solution favors the electrostatic repulsion between particles, helping the breakage of agglomerates. The corresponding countercation $\left(\mathrm{TPA}^{+}\right)$cannot interfere because of its relatively large size. In addition, no swelling by $\mathrm{CTA}^{+}$of the lamellar solid was observed[14], which was inferred from the corresponding XRD analysis (shown and discussed later). 

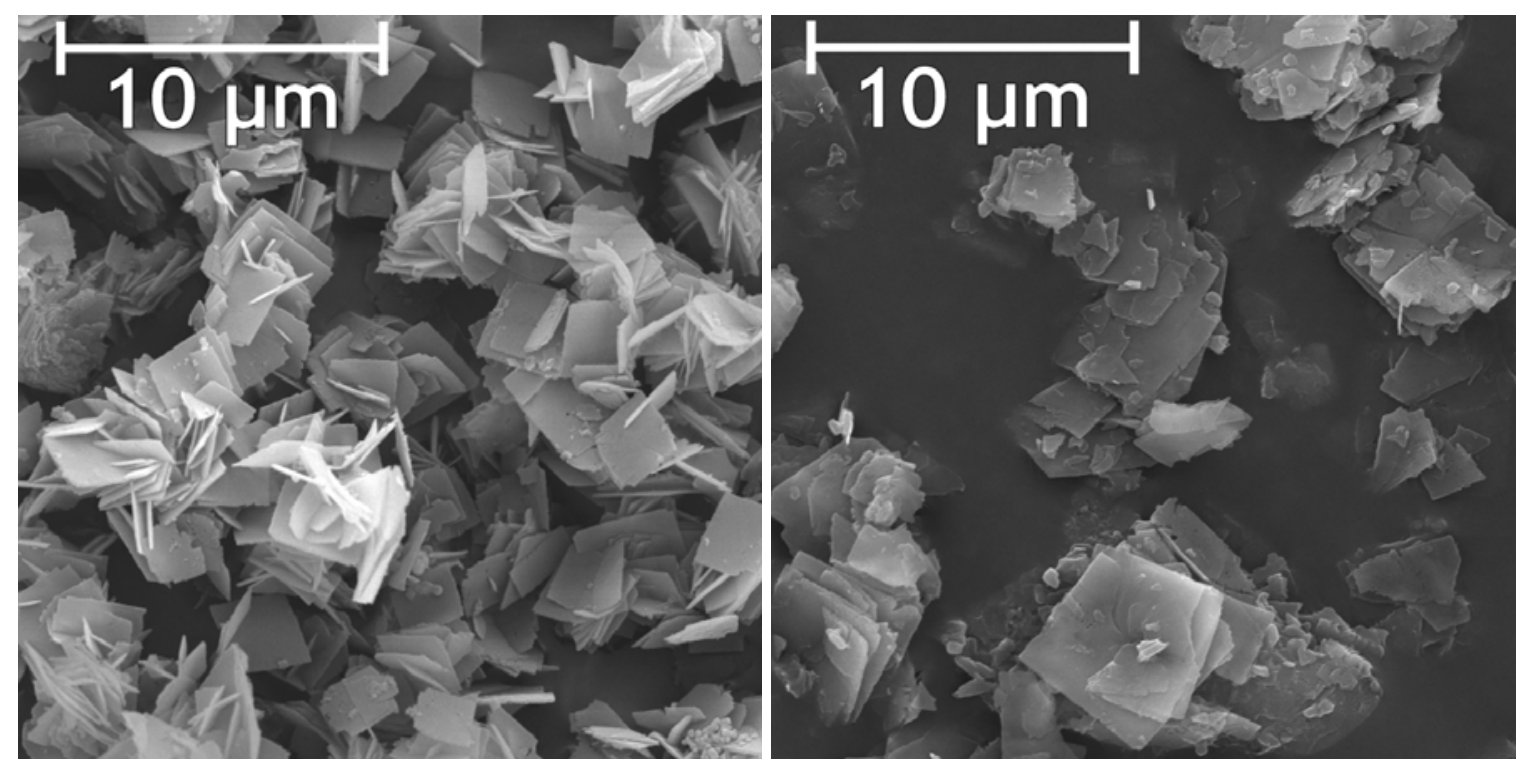

Figure 4. SEM images of as-made (left) and disaggregated (right) JDF-L1.

To gain a first impression on the orientation of the disaggregated JDF-L1 in the copolyimide matrix, the cross-sections of the MMMs were investigated using SEM. For this purpose, cross sectional pieces of the membrane were broken after freezing in liquid nitrogen. A long cross-section image was produced by combining nine successive SEM micrographs of a MMM cast from a $10 \mathrm{wt} \%$ polymer solution covering a length of $360 \mu \mathrm{m}$ (Figure S1 from the supporting information file). Exemplarily details from this combined image are shown in Figure 10. The broad area of the cross section indicates a good dispersion and an as-desired orientation of the JDF-L1 sheets, i.e. parallel to the membrane direction. Predominantly welldispersed and mainly horizontally oriented sheets of the inorganic filler can be observed in the mentioned figure.

Light microscopy was used for a magnified view through the membranes of the JDF-L1 sheets within the material (Figure 6). The sheets should appear as dark objects inside the bright polymer, which itself is transparent. It was expected that the horizontal orientation of the filler would lead to darker images compared to random orientation, in which the sheets should be observed more laterally. It is obvious that the membranes cast from $10 \mathrm{wt} \%$ 
polymer solutions show a significant decrease of brightness with increasing filler loads. This suggests a perpendicular orientation of the silicate sheets to the viewing direction. Accordingly, a horizontal orientation of filler material is assumed for these membranes. In case of the membranes cast from a $13 \mathrm{wt} \%$ polymer solution the decrease of brightness with higher loads of JDF-L1 is not as distinct. Thus, the inorganic material seems to be more randomly oriented in the corresponding membranes.

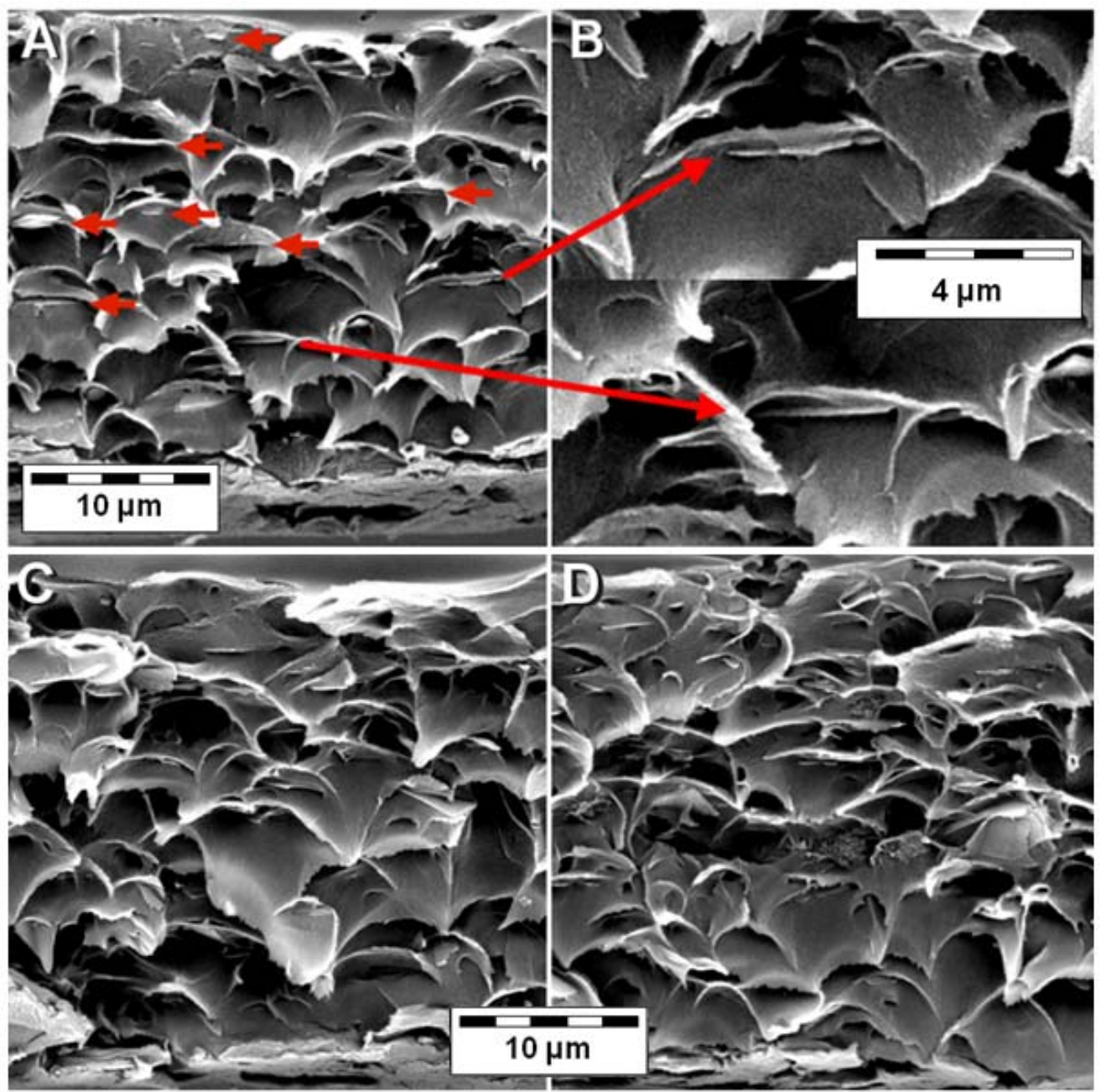

Figure 5. Details from a series of nine consecutive SEM images covering approximately 360 $\mu \mathrm{m}$ (see Figure S1) of the cross-section of a MMM cast from a $10 \mathrm{wt} \%$ polymer solution containing 8 wt \% JDF-L1 sheets: image 2 of 9 (A); magnification of two dispersed and horizontally oriented sheets (B); image 5 of 9 (C); and image 9 of 9 (D). 


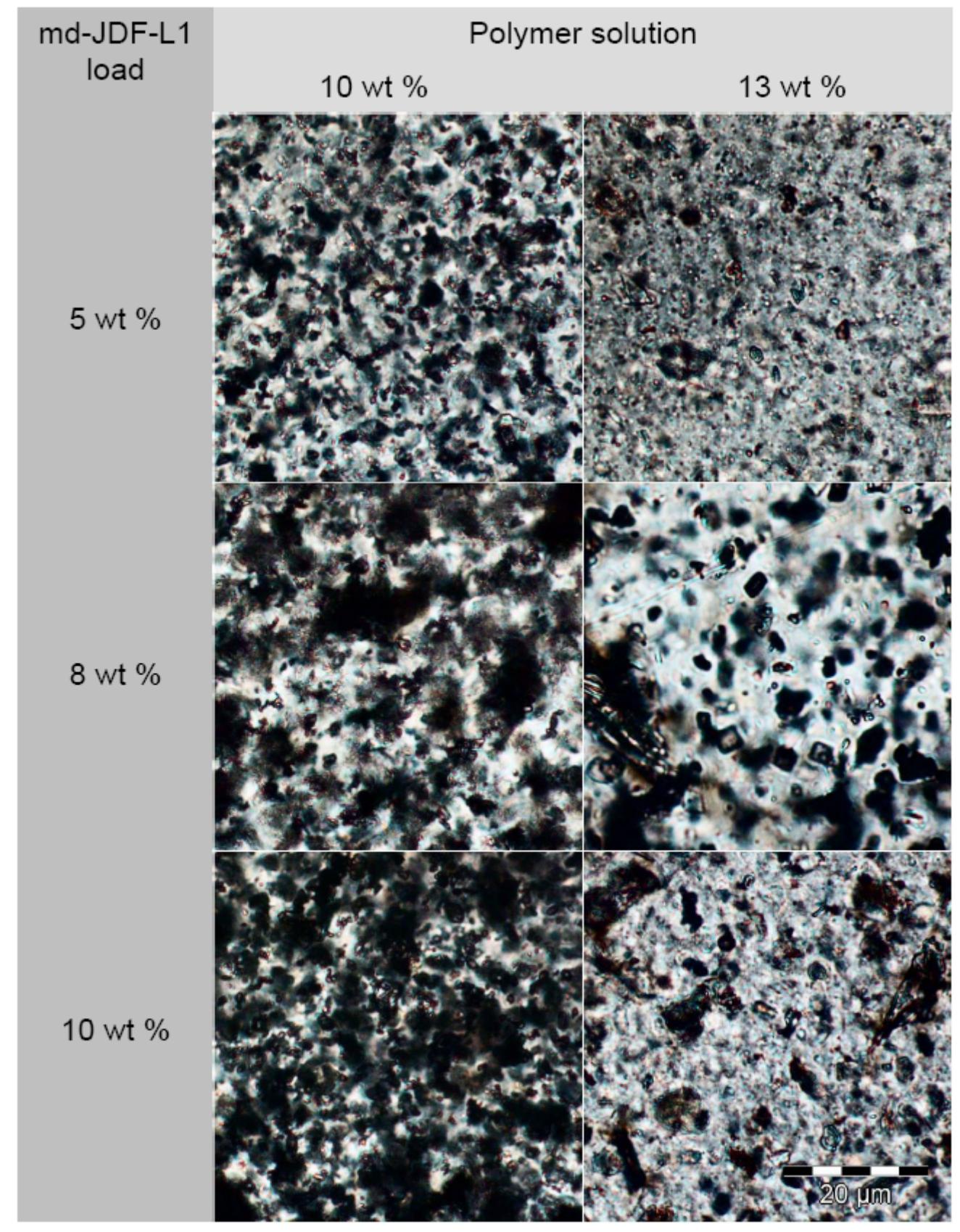

Figure 6. Light microscopy images of MMMs with different loads of JDF-L1 cast from copolyimide solutions of $10 \mathrm{wt} \%$ (left) and $13 \mathrm{wt} \%$ (right), respectively.

\subsection{Thermogravimetric analysis}

Thermogravimetric analyses were performed to determine the actual amount of inorganic filler in the MMMs, which should be similar to the theoretical values of the membranes. Moreover a good agreement of theoretical and experimental values would show a good dispersion of the inorganic filler in the casting solution and consequently also in the 
membrane. This is because a lack of homogeneity in the casting solution, whether due to insufficient dispersion or sedimentation prior to the membrane casting, will lead to a deviation between the theoretical and experimental filler loads. The exact amounts of filler material obtained were $7.0,8.7$, and $13 \mathrm{wt} \%$ when the nominal loads were 5,8 , and $10 \mathrm{wt} \%$, respectively. In addition, no weight loss was observed below $200{ }^{\circ} \mathrm{C}$, confirming that the thermal post-treatment of the membrane was efficient enough to remove traces of the remaining solvent. The results of the analysis are shown in Figure S2 in the supporting information file for MMMs cast from $10 \mathrm{wt} \%$ polymer solutions.

\subsection{X-ray diffraction}

By measuring diffraction patterns it is possible to obtain structural information of the inorganic filler before and after the disaggregation process as well as inside of the MMMs. Disaggregated JDF-L1 shows the same diffraction pattern as untreated or as-made JDF-L1 because the titanosilicate undergoes no structural changes during the disaggregation process (Figure 7). The only difference is expected due to the presence of singular sheets after the preparation. In addition, the MMMs should show peaks of JDF-L1 due to its dispersion throughout the polymer matrix. The corresponding peak intensities also yield information about sheet orientation. If they are oriented parallel the strongest peaks will be the ones related to the $[00 l]$ direction while the other peaks will show lower intensity or even disappear.

Following the reasoning described above, three main intensities are found in MMM containing $5 \mathrm{wt} \%$ disaggregated JDF-L1 (Figure 7). These peaks are located at $2 \cdot \theta=8.3^{\circ}$, $16.4^{\circ}$, and $24.8^{\circ}$, and correspond to [001], [002], and [003] crystallographic directions, respectively. This confirms that the inorganic material preserves its layered structure when incorporated into the polymer matrix. The main point is that disaggregated JDF-L1 is present in all membranes and shows a certain amount of orientation. This is because all spectra show 
the three above-mentioned signals related to the face of the nanosheets, but no other peaks (for instance those at $2 \cdot \theta=20.3^{\circ}, 25.4^{\circ}, 28.2^{\circ}$, and $34.9^{\circ}$ ). In case of a completely random filler orientation further peaks related to the JDF-L1 structure would be expected. Similar results were achieved with the higher 8 wt \% and 10 wt \% JDF-L1 loads (not shown).

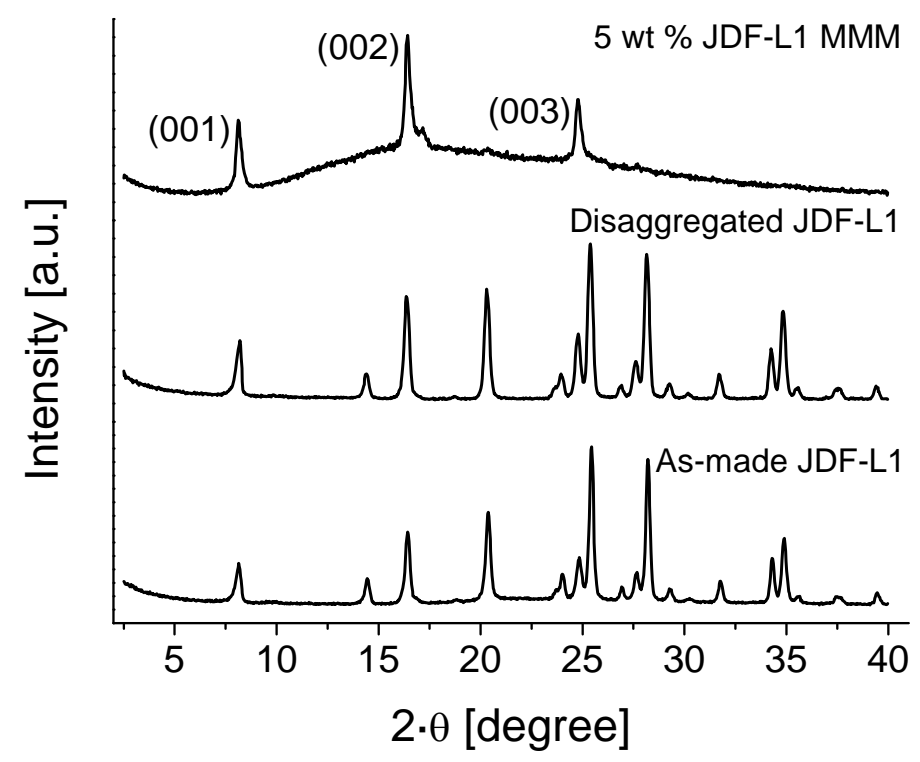

Figure 7. X-ray diffraction patterns of, from bottom to top: as-made JDF-L1, disaggregated JDF-L1, and a membrane with $5 \mathrm{wt} \%$ of disaggregated JDF-L1 cast from $10 \mathrm{wt} \%$ polymer solution.

It is expected that if the nanosheets are horizontally oriented within the MMMs the strongest reflections in X-ray diffraction are those related to the interlamellar distances in JDF-L1. The planes related to this horizontal orientation therefore are those corresponding to the [001], [002], and [003] directions. Changing the tilt of the sample holder should lead to a decrease of the intensity of these peaks, if the filler shows a horizontal orientation[3]. The [001] peak being the most suitable for this purpose, since it shows the highest intensity of the three and therefore provides the best indicator of any angle dependency. 
As shown in Figure 8, two membranes containing 8 wt $\%$ of JDF-L1 filler were measured using XRD at different tilt angles of the sample holder. When the sample was tilted to larger angles, the JDF-L1 peak at $2 \cdot \theta=8.25^{\circ}$ was measured; this reflex is related to the [001] direction. Despite the decline in intensity found for the two tested samples, a stronger decrease in the intensity of this peak at high tilt angles was found for the membrane cast from a $10 \mathrm{wt} \%$ polymer solution than for that cast from $13 \mathrm{wt} \%$ polymer solution. This correlates with a larger preferential horizontal orientation of the sheets inside the polymer matrix cast from $10 \mathrm{wt} \%$ solution.

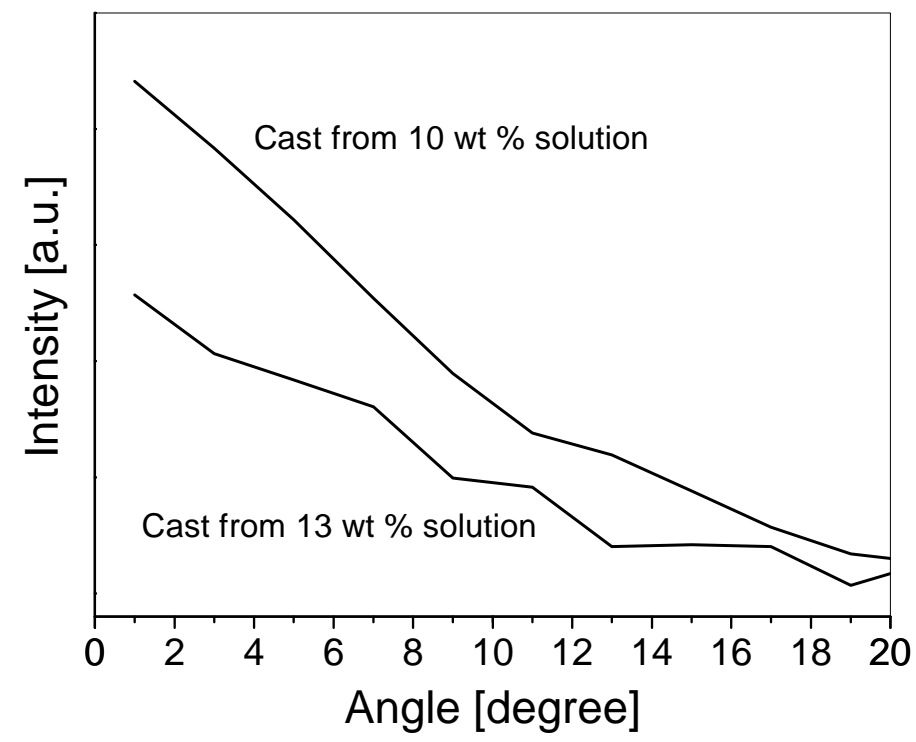

Figure 8. Angle dependant X-ray diffraction comparing MMMs cast from 10 and 13 wt \% polymer solutions containing $8 \mathrm{wt} \%$ disaggregated JDF-L1 each. The intensity of the peak related to the [001] direction at $2 \cdot \theta=8.25^{\circ}$ was measured at different tilt angles of the sample holder.

\subsection{Raman spectroscopy}

Polarized Raman spectroscopy was carried out, with the aim of obtaining further information about the orientation of the nanosheets. In these experiments, a linear polarized 
laser beam was focused on the surface of the membrane and the Raman signal was collected through a polarizer followed by a scrambler. From this observation, only small differences between parallel and perpendicular planes are expected if the material is randomly oriented. On the other hand, when the material is preferentially oriented, the differences between parallel and perpendicular spectra should increase with the degree of orientation.

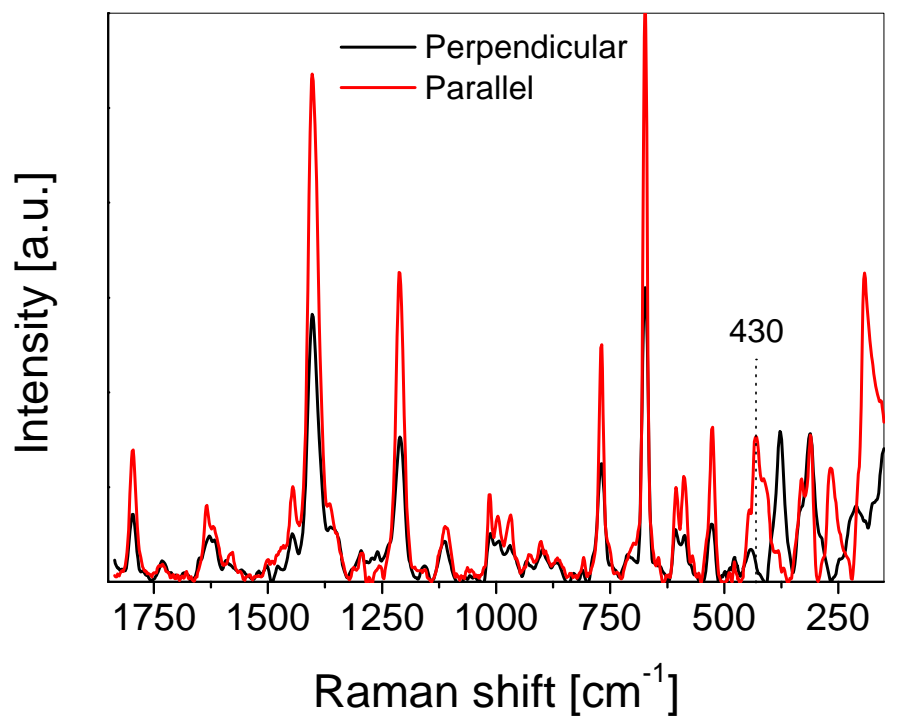

Figure 9. Raman spectra of a pure polymer membranes.

Most of the signals in the spectra are related to the polymer. Even though the polymeric matrix itself is not randomly oriented, as can be seen from the slight differences between the parallel and perpendicular polarized Raman spectra of the pure polymer (Figure 9), the addition of the nanosheets increases the polymer orientation since the polymer signals are affected to a higher degree. The changes between parallel and perpendicular spectra can be considered as a measure of the degree of orientation where a more pronounced variation of the Raman signals in the perpendicular spectra are a result of a higher degree of horizontal sheet orientation. With a perpendicular polarizer, the more remarkable effect due to the addition of the inorganic filler is the disappearance and narrowing of some signals in the 
spectral range between 500 and $200 \mathrm{~cm}^{-1}$. However, in the perpendicular spectra one strong polymer peak at $430 \mathrm{~cm}^{-1}$ also disappears. This allows us to observe a characteristic JDF-L1 related peak at $465 \mathrm{~cm}^{-1}$ (Figure 8) for MMMs containing $8 \mathrm{wt} \%$ of inorganic material. In good agreement with the XRD observations, when comparing the MMMs cast from $10 \mathrm{wt} \%$ and 13 wt $\%$ polymer solutions with equal filler load, the effect is stronger for membranes cast from $10 \mathrm{wt} \%$ polymer solution (see Figure 10 and 11).

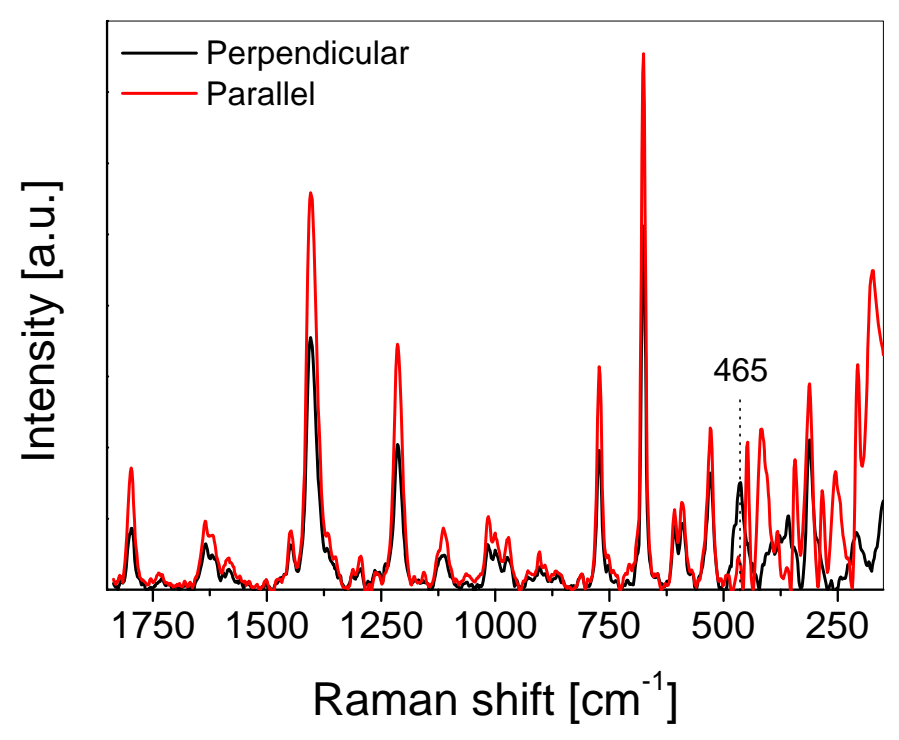

Figure 10. Raman spectra of a membrane cast from a $10 \mathrm{wt} \%$ polymer solution containing 8 wt \% disaggregated JDF-L1. 


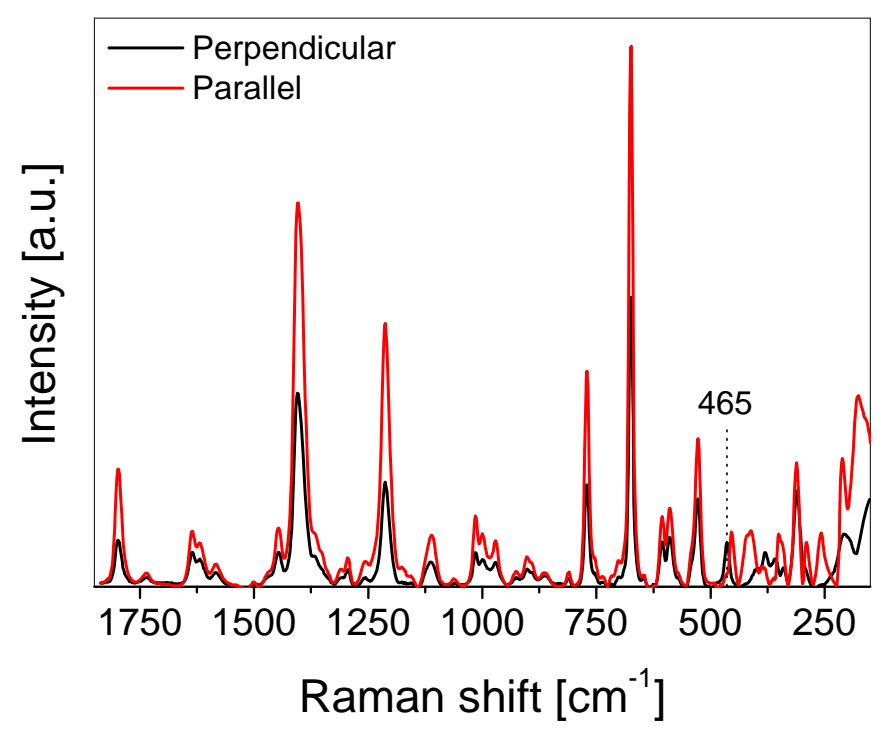

Figure 11. Raman spectra of a membrane cast from a 13 wt \% polymer solution containing 8 wt \% disaggregated JDF-L1.

\subsection{Gas permeation results}

MMMs containing $0,5,8$, and 10 wt \% of disaggregated JDF-L1 cast from 10 and 13 wt $\%$ polymer solutions were applied to the separation of $\mathrm{H}_{2} / \mathrm{CH}_{4}$ and $\mathrm{O}_{2} / \mathrm{N}_{2}$ mixtures. Since $\mathrm{H}_{2}, \mathrm{CH}_{4}, \mathrm{O}_{2}$, and $\mathrm{N}_{2}$ have kinetic diameters of $2.89,3.87,3.46$, and $3.64 \AA$, respectively, and the JDF-L1 pore size is about $3 \AA$ (in agreement with this JDF-L1 does not show relevant $\mathrm{N}_{2}$ adsorption $[14,36])$ an initial prediction of performance could be made for MMMs obtained here. $\mathrm{H}_{2}$ would be favored over $\mathrm{CH}_{4}$, while an important barrier action for $\mathrm{CH}_{4}, \mathrm{O}_{2}$, and $\mathrm{N}_{2}$ transport would be expected. In addition, a parallel preferential orientation of the JDF-L1 sheet particles in the polymer would increase these two effects.

In the case of the $\mathrm{H}_{2} / \mathrm{CH}_{4}$ mixture, the $\mathrm{H}_{2}$ permeability decreases as a function of the JDF-L1 loading, as shown in Figure 12. The permeability of $\mathrm{CH}_{4}$ drops more drastically than that of $\mathrm{H}_{2}$ resulting in a remarkable increase of the $\mathrm{H}_{2} / \mathrm{CH}_{4}$ selectivity. This suggests, as expected from the previous kinetic diameter analysis, that $\mathrm{H}_{2}$ molecules permeate through the 
microporous titanosilicate at a significant rate, while the filler is a very efficient barrier for $\mathrm{CH}_{4}$.
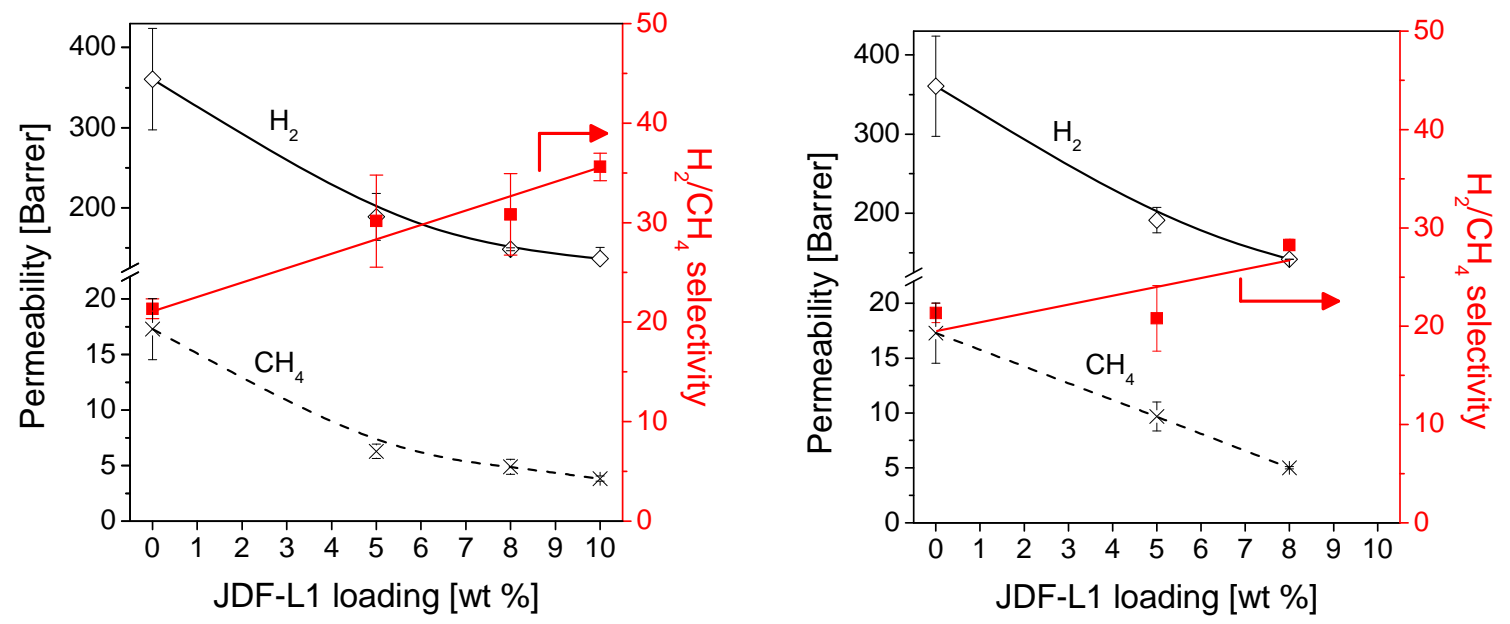

Figure $12 . \mathrm{H}_{2} / \mathrm{CH}_{4}$ separation experiments at $35{ }^{\circ} \mathrm{C}$ with MMMs cast from a $10 \mathrm{wt} \%$ (left) and $13 \mathrm{wt} \%$ (right) copolyimide solutions.

When comparing the results for $\mathrm{H}_{2} / \mathrm{CH}_{4}$ separation experiments for MMMs cast from $10 \mathrm{wt} \%$ polymer solution (Figure 12 , left) with those for MMMs cast from $13 \mathrm{wt} \%$ solution (Figure 12, right), a lower gain of selectivity by increasing amounts of JDF-L1 was found in the latter case. The more oriented the sheet particles are in the polymer matrix; the higher the reduction in $\mathrm{CH}_{4}$ permeability and the better the membrane performance in terms of $\mathrm{H}_{2} / \mathrm{CH}_{4}$ selectivity. This is in good agreement with the results from the light microscope images showing a higher orientation of the JDF-L1 sheets in the case of samples cast from $10 \mathrm{wt} \%$ polymer solution. In particular, for $5 \mathrm{wt} \%$ JDF-L1 loading, MMMs prepared from $10 \mathrm{wt} \%$ polymer solution have $\mathrm{H}_{2}$ and $\mathrm{CH}_{4}$ permeabilities of 189 and 6.3 Barrer, respectively, and a $\mathrm{H}_{2} / \mathrm{CH}_{4}$ selectivity of 30.2 . Whilst MMMs prepared from $13 \mathrm{wt} \%$ polymer solution have $\mathrm{H}_{2}$ and $\mathrm{CH}_{4}$ permeabilities of 191 and 9.7 Barrer, respectively, and $\mathrm{H}_{2} / \mathrm{CH}_{4}$ selectivityof 20.8 . For the pure polymer, $\mathrm{H}_{2}$ and $\mathrm{CH}_{4}$ permeabilities were 360 and 17 Barrer, respectively, and 
$\mathrm{H}_{2} / \mathrm{CH}_{4}$ selectivity was 21.3 . Thus, a good horizontal orientation produces an additional decrease in $\mathrm{CH}_{4}$ permeability enhancing the increase in selectivity which is due to the fact that $\mathrm{H}_{2}$ is able to permeate through the pores of the filler material. In any case, as shown, either less oriented or non-oriented particles can also increase the tortuosity of the molecular transport path giving rise to transport improvement.
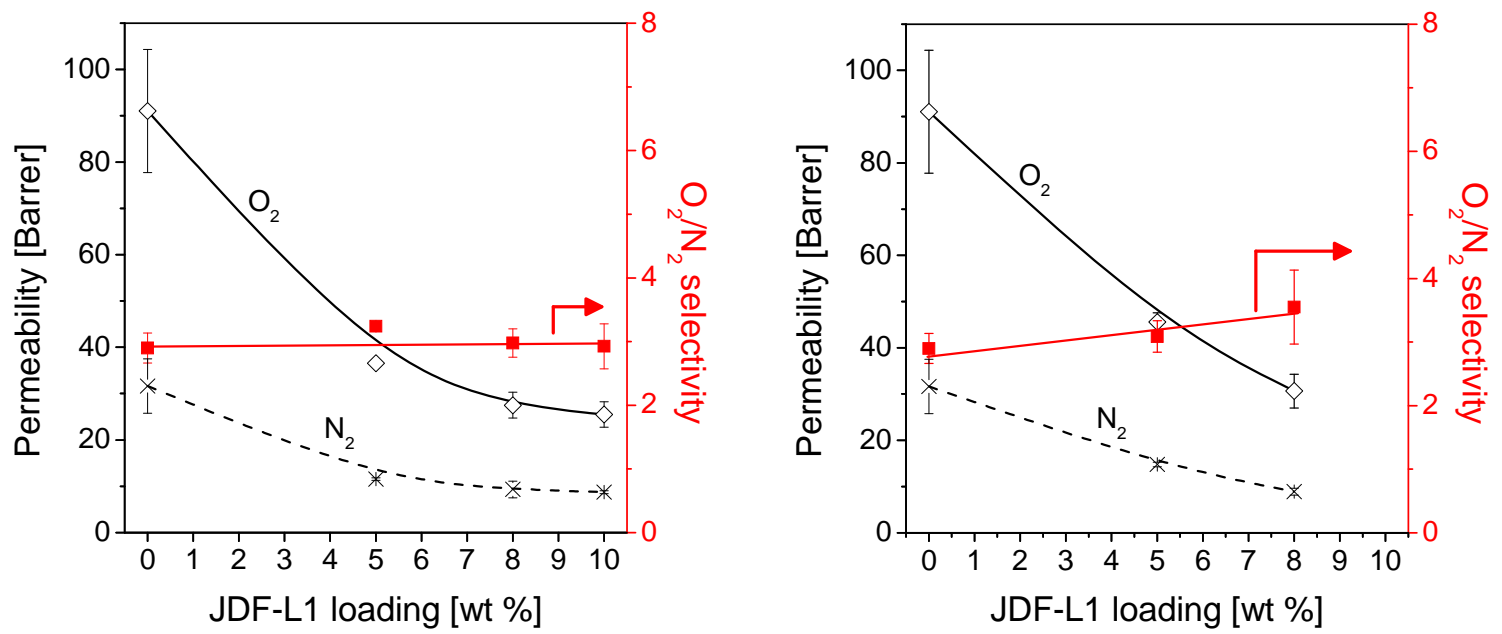

Figure $13 . \mathrm{O}_{2} / \mathrm{N}_{2}$ gas separation experiments at $35^{\circ} \mathrm{C}$ with MMMs cast from $10 \mathrm{wt} \%$ (left) and $13 \mathrm{wt} \%$ (right) copolyimide solutions.

Figure 13 shows separation results of the $\mathrm{O}_{2} / \mathrm{N}_{2}$ mixture with MMMs cast from $10 \mathrm{wt}$ $\%$ (left) and 13 wt \% (right) polymer solutions with different amounts of filler load. None of the molecules in this gas-mixture can permeate through the silicate sheets. Therefore, the increasing amount of JDF-L1 reduces the permeation of both gases while the selectivity accordingly remains approximately constant. Whether the orientation of the filler sheets is predominantly horizontal or more randomly has only little influence on the $\mathrm{O}_{2} / \mathrm{N}_{2}$ selectivity (which was 2.9 for the pure polymer, and 3.2 and 3.1 for MMMs cast with $10 \mathrm{wt} \%$ and $13 \mathrm{wt}$ $\%$ polymer solutions, respectively). However, the preferential horizontal orientation reached at $10 \mathrm{wt} \%$ polymer solution produces a stronger barrier effect in terms of reducing $\mathrm{O}_{2}$ 
permeability, which may be of interest in certain areas related to active packaging[37]. For instance, for 5 and $8 \mathrm{wt} \%$ JDF-L1 loading, MMMs prepared from $10 \mathrm{wt} \%$ polymer solution have lower $\mathrm{O}_{2}$ permeabilites (36.7 and 27.5 Barrer, respectively) than MMMs prepared from $13 \mathrm{wt} \%$ polymer solution (45.6 and 30.7 Barrer, respectively) whereas an $\mathrm{O}_{2}$ permeability of 91.1 Barrer was found for the pure polymer. Finally, Figures S3 and S4 from the supporting information file show both $\mathrm{H}_{2} / \mathrm{CH}_{4}$ and $\mathrm{O}_{2} / \mathrm{N}_{2}$ separation results by plotting the selectivities as a function of permeabilities.

\section{Conclusion}

The agglomerates of the titanosilicate JDF-L1 can be disaggregated to obtain a mainly sheet shaped material. Different amounts of this material were successfully incorporated as an inorganic phase into MMMs with the polyimide 6FDA-4MPD/6FDA DABA 4:1. It was shown by the use of angle dependant X-ray diffraction, Raman spectroscopy, optical microscopy and SEM measurements that a $10 \mathrm{wt} \%$ polymer solution is best suited to obtain a preferential horizontal orientation of the inorganic material. However, good dispersion of the inorganic material was found for MMMs cast from $13 \mathrm{wt} \%$ polymer solution as well, even though this solution appears to be too viscous to allow preferential orientation of the inorganic material.

Measurements with the $\mathrm{H}_{2} / \mathrm{CH}_{4}$ mixture showed that the selectivity for $\mathrm{H}_{2}$ increases with higher amounts of filler material. This effect is more pronounced for the membranes cast from a $10 \mathrm{wt} \%$ polymer solution. The results from these samples are in good agreement with the preferential horizontal orientation found in these MMMs. The different kinetic diameters of the two gases can be given as a reason for this result. $\mathrm{H}_{2}$ molecules are able to permeate through the JDF-L1 sheets, whereas $\mathrm{CH}_{4}$ molecules are restricted to the polymeric phase during their diffusion through the membrane. The maximum increase in $\mathrm{H}_{2} / \mathrm{CH}_{4}$ selectivity was achieved with a MMM cast from a $10 \mathrm{wt} \%$ polymer solution and containing $10 \mathrm{wt} \%$ of 
disaggregated JDF-L1. In this case the selectivity increased from 21.3 for the pure polymer to 35.6 in the MMM.

For the separation of the $\mathrm{O}_{2} / \mathrm{N}_{2}$ mixture, the kinetic diameters of both gases are too large for the permeation through the JDF-L1 sheets. Therefore, the preferential orientation of the filler reached at $10 \mathrm{wt} \%$ casting solutions does not affect the $\mathrm{O}_{2} / \mathrm{N}_{2}$ selectivity but produces a stronger barrier effect in terms of reducing $\mathrm{O}_{2}$ permeability.

\section{Acknowledgments}

We gratefully thank the German Academic Exchange Service (DAAD) for the financial support within the budget of the project related person exchange program (PPP, 0804142). Also, financial support from the Spanish Science and Innovation Ministry (MAT2007-61028, CIT-420000-2009-32, and HD2008-0001) and the Aragon Government (PI035/09) is gratefully acknowledged.

\section{References}

[1] T.S. Chung, L.Y. Jiang, Y. Li, S. Kulprathipanja, Mixed matrix membranes (MMMs) comprising organic polymers with dispersed inorganic fillers for gas separation, Prog. Polym. Sci. 32 (2007) 483-507.

[2] L.M. Robeson, The upper bound revisited, J. Membr. Sci. 320 (2008) 390-400.

[3] C.F. Yang, W.H. Smyrl, E.L. Cussler, Flake alignment in composite coatings, J. Membr. Sci. 231 (2004) 1-12.

[4] H.K. Jeong, W. Krych, H. Ramanan, S. Nair, E. Marand, M. Tsapatsis, Fabrication of polymer/selective-flake nanocomposite membranes and their use in gas separation, Chem. Mater. 16 (2004) 3838-3845.

[5] I. Frankel, H. Brenner, Taylor dispersion of orientable Brownian particles in unbounded homogeneous shear flows, J. Fluid Mechan. 255 (1993) 129-156.

[6] J.R. Johnson, W.J. Koros, Utilization of nanoplatelets in organic-inorganic hybrid separation materials: Separation advantages and formation challenges, J. Taiwan Inst. Chem. Eng. 40 (2009) 268-275.

[7] J.A. Sheffel, M. Tsapatsis, A model for the performance of microporous mixed matrix membranes with oriented selective flakes, J. Membr. Sci. 295 (2007) 50-70.

[8] A. Corma, V. Fornes, S.B. Pergher, T.L.M. Maesen, J.G. Buglass, Delaminated zeolite precursors as selective acidic catalysts, Nature 396 (1998) 353-356.

[9] W.B. Fan, P. Wu, S. Namba, T. Tatsumi, Synthesis and catalytic properties of a new titanosilicate molecular sieve with the structure analogous to MWW-type lamellar precursor, J. Catal. 243 (2006) 183-191. 
[10] L. Liu, M.J. Cheng, D. Ma, G. Hu, X.L. Pan, X.H. Bao, Synthesis, characterization, and catalytic properties of MWW zeolite with variable Si/Al ratios, Microporous Mesoporous Mater. 94 (2006) 304-312.

[11] P. Wu, D. Nuntasri, J.F. Ruan, Y.M. Liu, M.Y. He, W.B. Fan, O. Terasaki, T. Tatsumi, Delamination of Ti-MWW and high efficiency in epoxidation of alkenes with various molecular sizes, J. Phys. Chem. B 108 (2004) 19126-19131.

[12] Y. Hudiono, S. Choi, S. Shu, W.J. Koros, M. Tsapatsis, S. Nair, Porous layered oxide/Nafion (R) nanocomposite membranes for direct methanol fuel cell applications, Microporous Mesoporous Mater. 118 (2009) 427-434.

[13] S. Choi, J. Coronas, E. Jordan, W. Oh, S. Nair, F. Onorato, D.F. Shantz, M. Tsapatsis, Layered silicates by swelling of AMH-3 and nanocomposite membranes, Angew. Chem. Int. Ed. 47 (2008) 552-555.

[14] C. Rubio, C. Casado, P. Gorgojo, F. Etayo, S. Uriel, C. Téllez, J. Coronas, Exfoliated Titanosilicate Material UZAR-S1 Obtained from JDF-L1, Eur. J. Inorg. Chem. (2010) 159163.

[15] J. Rocha, M.W. Anderson, Microporous titanosilicates and other novel mixed octahedral-tetrahedral framework oxides, Eur. J. Inorg. Chem. (2000) 801-818.

[16] J. Rocha, Z. Lin, Microporous mixed octahedral-pentahedral-tetrahedral framework silicates, Rev. Mineral Geochem. 57 (2005) 173-201.

[17] M. Veltri, D. Vuono, P. De Luca, J.B. Nagy, A. Nastro, Typical data of a new microporous material obtained from gels with titanium and silicon, J. Therm. Anal. Cal. 84 (2006) 247-252.

[18] M.A. Roberts, G. Sankar, J.M. Thomas, R.H. Jones, H. Du, J. Chen, W. Pang, R. Xu, Synthesis and structure of a layered titanosilicate catalyst with five-coordinate titanium, Nature 381 (1996) 401-404.

[19] S. Ferdov, U. Kolitsch, C. Lengauer, E. Tillmanns, Z. Lin, R.A.S. Ferreira, Refinement of the layered titanosilicate AM-1 from single-crystal X-ray diffraction data, Acta Crystallogr., Sect. E: Struct. Rep. Online 63 (2007) I186-U120.

[20] C. Rubio, C. Casado, S. Uriel, C. Téllez, J. Coronas, Seeded synthesis of layered titanosilicate JDF-L1, Mater. Lett. 63 (2009) 113-115.

[21] A. Philippou, M.W. Anderson, Aldol-type reactions over basic microporous titanosilicate ETS-10 type catalysts, J. Catal. 189 (2000) 395-400.

[22] M. Di Serio, R. Tesser, L. Pengmei, E. Santacesaria, Heterogeneous catalysts for biodiesel production, Energy Fuels 22 (2008) 207-217.

[23] S.B. Waghmode, R. Vetrivel, S.G. Hegde, C.S. Gopinath, S. Sivasanker, Physicochemical investigations of the basicity of the cation exchanged ETS-10 molecular sieves, J. Phys. Chem. B 107 (2003) 8517-8523.

[24] A. Anson, C.C.H. Lin, S.M. Kuznicki, J.A. Sawada, Adsorption of carbon dioxide, ethane, and methane on titanosilicate type molecular sieves, Chem. Eng. Sci. 64 (2009) 36833687.

[25] J.P. DeRocher, B.T. Gettelfinger, J.S. Wang, E.E. Nuxoll, E.L. Cussler, Barrier membranes with different sizes of aligned flakes, J. Membr. Sci. 254 (2005) 21-30.

[26] L. Yang, J. Fang, N. Meichin, K. Tanaka, H. Kita, K. Okamoto, Gas permeation properties of thianthrene-5,5,10,10-tetraoxide-containing polyimides, Polymer 42 (2001) 2021-2029.

[27] M. Yoshino, S. Nakamura, H. Kita, K. Okamoto, N. Tanihara, Y. Kusuki, Olefin/paraffin separation performance of carbonized membranes derived from an asymmetric hollow fiber membrane of 6FDA/BPDA-DDBT copolyimide, J. Membr. Sci. 215 (2003) 169183. 
[28] J.H. Ren, R. Wang, T.S. Chung, D.F. Li, Y. Liu, The effects of chemical modifications on morphology and performance of 6FDA-ODA/NDA hollow fiber membranes for $\mathrm{CO} 2 / \mathrm{CH} 4$ separation, J. Membr. Sci. 222 (2003) 133-147.

[29] S. Hess, C. Staudt-Bickel, R.N. Lichtenthaler, Propene/propane separation with copolyimide membranes containing silver ions, J. Membr. Sci. 275 (2006) 52-60.

[30] D.M. Munoz, E.M. Maya, J. de Abajo, J.G. de la Campa, A.E. Lozano, Thermal treatment of poly(ethylene oxide)-segmented copolyimide based membranes: An effective way to improve the gas separation properties, J. Membr. Sci. 323 (2008) 53-59.

[31] Y. Kashimura, S. Aoyama, H. Kawakami, Gas Transport Properties of Asymmetric Block Copolyimide Membranes, Polym. J. 41 (2009) 961-967.

[32] K. Tanaka, M. Okano, H. Toshino, H. Kita, K.I. Okamoto, Effect of methyl substituents on permeability and permselectivity of gases in polyimides prepared from methyl-substituted phenylenediamined, Journal of Polymer Science Part B-Polymer Physics 30 (1992) 907-914.

[33] C. Staudt-Bickel, W.J. Koros, Improvement of CO2/CH4 separation characteristics of polyimides by chemical crosslinking, Journal of Membrane Science 155 (1999) 145-154.

[34] C. Staudt-Bickel, Cross-linked copolyimide membranes for the separation of gaseous and liquid mixtures, Soft Mater. 1 (2003) 277-293.

[35] S.A. Stern, Y. Mi, H. Yamamoto, A.K. Stclair, Structure permeability relationships of polyimide membranes. Applications to the separation of gas-mixtures, J. Polym. Sci., Part B: Polym. Phys. 27 (1989) 1887-1909.

[36] Z. Lin, J. Rocha, P. Brandao, A. Ferreira, A.P. Esculcas, J.D.P. deJesus, A. Philippou, M.W. Anderson, Synthesis and structural characterization of microporous umbite, penkvilksite, and other titanosilicates, J. Phys. Chem. B 101 (1997) 7114-7120.

[37] S. Amberg-Schwab, U. Weber, A. Burger, S. Nique, R. Xalter, Development of passive and active barrier coatings on the basis of inorganic-organic polymers, Monatsh. Chem. 137 (2006) 657-666. 


\section{Figure captions}

Figure 6. Structure of the titanosilicate JDF-L1 (top view onto layer, along [001] direction). Grey, $\mathrm{TiO}_{5}$ square pyramids; yellow, $\mathrm{SiO}_{4}$ tetrahedra; red, oxygen atoms (both from polyhedra corners and water molecules hydrating $\mathrm{Na}^{+}$); purple, $\mathrm{Na}^{+}$ions .

Figure 7. Structure of the copolyimide 6FDA-4MPD/6FDA-DABA 4:1.

Figure 8. Experimental setup of the gas permeation system

Figure 9. SEM images of as-made (left) and disaggregated (right) JDF-L1.

Figure 10. Details from a series of nine consecutive SEM images covering approximately 360 $\mu \mathrm{m}$ (see Figure S1) of the cross-section of a MMM cast from a $10 \mathrm{wt} \%$ polymer solution containing 8 wt \% JDF-L1 sheets: image 2 of 9 (A); magnification of two dispersed and horizontally oriented sheets (B); image 5 of 9 (C); and image 9 of 9 (D).

Figure 6. Light microscopy images of MMMs with different loads of JDF-L1 cast from copolyimide solutions of $10 \mathrm{wt} \%$ (left) and $13 \mathrm{wt} \%$ (right), respectively.

Figure 7. X-ray diffraction patterns of, from bottom to top: as-made JDF-L1, disaggregated JDF-L1, and a membrane with $5 \mathrm{wt} \%$ of disaggregated JDF-L1 cast from $10 \mathrm{wt} \%$ polymer solution.

Figure 8. Angle dependant X-ray diffraction comparing MMMs cast from 10 and 13 wt \% polymer solutions containing $8 \mathrm{wt} \%$ disaggregated JDF-L1 each. The intensity of the peak related to the [001] direction at $2 \cdot \theta=8.25^{\circ}$ was measured at different tilt angles of the sample holder.

Figure 9. Raman spectra of a pure polymer membrane.

Figure 10. Raman spectra of a membrane cast from a $10 \mathrm{wt} \%$ polymer solution containing 8 wt \% disaggregated JDF-L1.

Figure 11. Raman spectra of a membrane cast from a $13 \mathrm{wt} \%$ polymer solution containing 8 wt \% disaggregated JDF-L1. 
Figure $12 . \mathrm{H}_{2} / \mathrm{CH}_{4}$ separation experiments at $35{ }^{\circ} \mathrm{C}$ with MMMs cast from a $10 \mathrm{wt} \%$ (left) and $13 \mathrm{wt} \%$ (right) copolyimide solutions.

Figure $13 . \mathrm{O}_{2} / \mathrm{N}_{2}$ separation experiments at $35{ }^{\circ} \mathrm{C}$ with MMMs cast from $10 \mathrm{wt} \%$ (left) and 13 wt \% (right) copolyimide solutions. 